\title{
Mechanical failures after fixation with proximal femoral nail and risk factors
}

\author{
This article was published in the following Dove Press journal: \\ Clinical Interventions in Aging \\ 17 December 2015 \\ Number of times this article has been viewed
}

\section{Șemmi Koyuncu' \\ Tașkın Altay² \\ Cemil Kayalı \\ Firat Ozan ${ }^{3}$ \\ Kamil Yamak ${ }^{2}$}

'Department of Orthopedics and Traumatology, Bayburt State Hospital, Bayburt, ${ }^{2}$ Department of Orthopedics and Traumatology, İzmir Bozyaka Training and Research Hospital, İzmir, ${ }^{3}$ Department of Orthopedics and Traumatology, Kayseri Training and Research Hospital, Kayseri, Turkey
Correspondence: Semmi Koyuncu Department of Orthopedics and Traumatology, Bayburt State Hospital, Șingah Mah İbni Sina Cad No 25,

Bayburt, Turkey

Tel +904582222300

Fax +904582119203

Email semmi2446@gmail.com
Background: This study aims at assessing the clinical results, radiographic findings, and associated complications after osteosynthesis of trochanteric hip fractures with proximal femoral nail (PFN).

Methods: A total of 152 patients with hip fractures who underwent osteosynthesis with PFN were included. The hip fracture types in the patients included in the study were classified according to the American Orthopedic/Orthopedic Trauma Association (AO/OTA). $\mathrm{AO} / \mathrm{OTA} \mathrm{A} 1, \mathrm{~A} 2$, and A3 type fractures were found in 24 (15.8\%), 107 (70.4\%), and 21 (13.8\%) patients, respectively. The Baumgaertner scale was used to assess the degree of postoperative reduction. The Salvati-Wilson hip function (SWS) scoring system was used to evaluate functional results. After a follow-up period, clinical and radiographic results were evaluated and complications were assessed. The relationship between the complications and SWS score, age, sex, fracture type, reduction quality, and time from the fracture to surgery was evaluated.

Results: Eighty-five (55.9\%) female patients and 67 (44.1\%) male patients were enrolled in the study. Seventy-nine (51.9\%) patients had left hip fractures, and 73 (48.1\%) had right hip fractures. The mean age was 76 (range 21-93) years, and the mean follow-up duration was 23.6 (range 7-49) months. Postoperatively, one patient ( $0.6 \%$ ) had a poor reduction, 16 patients $(10.5 \%)$ had an acceptable reduction, and 135 patients $(88.9 \%)$ had a good reduction according to the above criteria. The SWS scores were excellent, good, moderate, and poor in $91(59.8 \%)$, $45(29.6 \%), 15(9.8 \%)$, and one (0.6\%) patients, respectively. Late postoperative complications were seen in 27 patients (17.7\%). A total of 14 patients $(9.2 \%)$ underwent a revision procedure for mechanical complications.

Conclusion: The study results suggest that the quality of fracture reduction is an important factor that affects the revision rate and SWS score in patients with mechanical complications after osteosynthesis with PFN for trochanteric fractures.

Keywords: trochanteric hip fracture, proximal femoral nail, fracture reduction, complications, risk factors, intramedullary nail

\section{Introduction}

Trochanteric femoral fractures are often seen in patients aged $>65$ years; they can be caused by high-energy or low-energy trauma or may be pathological in nature. ${ }^{1-4}$ Particularly in the elderly, hip fractures are a major cause of increased mortality and morbidity. ${ }^{4,5}$ Because of the decreased physical capacity, concomitant systemic diseases, and increased vulnerability to environmental dangers, even low-energy trauma can cause unstable femoral trochanteric fractures in this age group..$^{5-7}$ Surgical management of hip fractures is targeted to help patients recover to the closest degree of functionality they had prior to the trauma; this is achieved by utilizing the most appropriate treatment methods and early ambulation, thereby preventing potential complications. ${ }^{6,8}$ 
Fractures involving the trochanteric area of the proximal femur are classified according to the American Orthopedic/ Orthopedic Trauma Association (AO/OTA) classification system as AO/OTA 31-A, which delineates them as extracapsular fractures of the hip. These fractures are then subdivided into groups A1, A2, and A3. Simple, two-part fractures are classified as A1 fractures, whereas A2 fractures have multiple fragments. More complex fractures, including reverse oblique and transverse fracture patterns, are classified as A3. ${ }^{9}$ The current approach for fractures involving the intertrochanteric region is to initially perform an anatomical reduction and then stabilize the fracture with rigid fixation. ${ }^{10}$ Cephalomedullary nails, such as the gamma nail and proximal femoral nail (PFN), are the preferred implants in proximal extracapsular femoral fractures $(\mathrm{AO} / \mathrm{OTA}$ 31-A). ${ }^{2,8,10,11}$ Compared with other implants, cephalomedullary nails provide biomechanical advantages because of their shorter lever arms and decreased deformity forces. ${ }^{2,7,8,10}$ They are the acceptable and preferred implants in the treatment of proximal femoral fractures, specifically because they allow for a closed reduction procedure. ${ }^{2,8,1-13}$ In addition, intramedullary fixation is associated with decreased soft tissue trauma, decreased blood loss, and lower rates of infection and wound complications. ${ }^{2,8,11,12}$ A meta-analysis by Ma et $\mathrm{al}^{14}$ reported less blood loss and shorter length of hospital stay with proximal femoral nail antirotation (PFNA). Also, they found no significant difference in the rate of fixation failure between the gamma nail and PFNA or dynamic hip screw (DHS). Similarly, Shen et a ${ }^{15}$ reported less blood loss and fewer complications in the PFNA group when compared to DHS group.

On the other hand, various complications may develop in the intraoperative and postoperative periods with the use of PFN. ${ }^{1,3,8,10,12,16-20}$ The potential late complications may include neck screw cutouts, nonunion, Z-effect, reversed Z-effect, secondary varus deformity, thigh pain due to iliotibial tract irritation, and fracture development near the distal aspect of the nail.

This study evaluates the clinical results, radiographic findings, and associated complications in patients who underwent osteosynthesis with PFN for fracture of the proximal femur.

\section{Materials and methods}

Between January 2009 and July 2013, 202 patients were operated with PFN for trochanteric fracture of the proximal femur. Among them, 152 patients (152 hips) who were followed up for at least 6 months were included in the study. According to the AO/OTA classification criteria, A1, A2, and
A3 type fractures were found in 24 (15.8\%), 107 (70.4\%), and $21(13.8 \%)$ patients, respectively.

The mean time from hip fracture to osteosynthesis with PFN was 3.75 (range 1-13) days, and titanium alloy PROFIN PFN ${ }^{\circledR}$ nails (TST Medical Devices, Istanbul, Turkey) were used. Surgery was performed under spinal anesthesia using fluoroscopy-guided closed reduction on a traction table. All patients were ambulated on the first day after surgery with partial weight-bearing according to their pain tolerance levels. The mean duration of hospital stay was 6.05 (range 1-24) days. Postoperative reduction was assessed using the Baumgaertner et al's scale. ${ }^{21}$ Functional results were evaluated using the Salvati and Wilson assessment score (SWS) ${ }^{22}$ (Table 1). After the follow-up period, clinical and radiographic results were evaluated and the complications were assessed. Intraoperative complications were excluded. Late complications, including implant cutout, Z-effect, reverse Z-effect, calcification of the tip of the greater trochanter, femoral neck shortening, nonunion, malunion, cortical thickening at the distal locking region, broken locking screw, broken PFN, and diaphyseal femoral fractures, were considered during radiographic assessment. The relationship between the complications and SWS

Table I Salvati and Wilson assessment score

\begin{tabular}{ll}
\hline & Scores \\
\hline Pain & \\
Constant and unbearable, frequent strong analgesia & 0 \\
Constant but bearable, occasional strong analgesia & 2 \\
None or little pain at rest, pain with activities & 4 \\
Little pain at rest, pain on activity & 6 \\
Occasional slight pain & 8 \\
No pain & 10 \\
Walking & \\
Bedridden & 0 \\
Wheelchair & 2 \\
Walking frame & 4 \\
One stick, limited distances up to 400 yards & 6 \\
One stick, long distances & 8 \\
Unaided and unrestricted & 10 \\
Muscle power and motion & \\
Ankylosing and deformity & 0 \\
Ankylosing with good functional position & 2 \\
Poor muscle power; flexion $<60^{\circ} ;$ abduction $<10^{\circ}$ & 4 \\
Fair muscle power; flexion $60^{\circ}-90^{\circ}$; abduction $10^{\circ}-20^{\circ}$ & 6 \\
Good muscle power; flexion $>90^{\circ} ;$ abduction $>20^{\circ}$ & 8 \\
Normal muscle power; full range of movement & 10 \\
Function & \\
Bedridden & 10 \\
House-bound & 0 \\
Limited housework & 2 \\
Most housework & \\
Normal activities & 4 \\
\hline
\end{tabular}


score, age, sex, fracture type, reduction quality, and time from fracture to surgery was evaluated. This study was conducted in accordance with the ethical guidelines of the Declaration of Helsinki and informed written consent was obtained from all the patients. The protocol was reviewed and approved by the Institutional Review Board of İzmir Bozyaka Training and Research Hospital, İzmir, Turkey (No. 16.03.2011-34).

\section{Statistical analysis}

Statistical analysis was performed using PASW version 18.0 software (SPSS Inc., Chicago, IL, USA). Frequency analysis was performed for categorical variables. The data were expressed in numbers and percentages. The Pearson chi-square test was used to compare categorical variables. A $P$-value of $<0.05$ was considered statistically significant.

\section{Results}

Of the patients, 85 (55.9\%) were females and 67 (44.1\%) were males. The mean age was 76 (range 21-93) years, and the mean follow-up duration was 23.6 (range 7-49) months. Seventy-nine patients (51.9\%) had left hip fractures, and 73 (48.1\%) had right hip fractures. The mechanism of fracture was a simple fall in 146 patients (96.1\%), a car accident in four patients $(2.6 \%)$, and a motorcycle accident in two patients $(1.3 \%)$. The mean duration of the operation was 63.35 (range 50-85) minutes. The demographic characteristics of the patients are shown in Table 2.

The initial postoperative radiographic assessment revealed that reduction was poor in one patient $(0.6 \%)$, acceptable in 16 patients $(10.5 \%)$, and good in 135 patients $(88.9 \%)$. The SWS scores were excellent, good, moderate, and poor in 91 (59.8\%), 45 (29.6\%), 15 (9.8\%), and one $(0.6 \%)$ patients, respectively. No pulmonary embolism or deep vein thrombosis, or no urinary tract infection or deep surgical site infection were observed in our study.

Table 2 Demographic characteristics of patients

\begin{tabular}{ll}
\hline Number of patients & I52 (I52 hips) \\
Age, mean (range) (years) & $76(2 \mathrm{I}-93)$ \\
Sex, $\mathrm{n}(\%)$ & \\
$\quad$ Female & $85(55.9)$ \\
$\quad$ Male & $67(44.1)$ \\
Location, $\mathrm{n}(\%)$ & \\
$\quad$ Right hip & $79(5 \mathrm{I} .9)$ \\
Left hip & $73(48.1)$ \\
Type of fracture (AO/OTA), n (\%) \\
Al \\
A2 & $24(15.8)$ \\
A3 & $107(70.4)$ \\
\hline
\end{tabular}

Abbreviation: AO/OTA, American Orthopedic/Orthopedic Trauma Association.
Superficial incision site infection was observed in two $(1.3 \%)$ patients. Infection resolved with antibiotic therapy and wound care.

Late postoperative complications were seen in 27 patients (17.7\%) (Table 3). Fourteen patients $(9.2 \%)$ underwent a revision procedure for mechanical complications (Figure 1). Of these, three $(1.9 \%)$ underwent a revision procedure for nonunion. One patient $(0.6 \%)$ underwent a $95^{\circ}$ dynamic condylar screw, whereas the remaining two patients $(1.3 \%)$ underwent a partial hip arthroplasty. In addition, one patient $(0.6 \%)$ with implant cutout underwent a partial hip arthroplasty, and two patients $(1.3 \%)$ with implant cutout underwent a total hip arthroplasty.

In one patient $(0.6 \%)$ with reverse Z-effect, one of the femoral head screws was removed without any additional surgical intervention. In another patient $(0.6 \%)$, the nail was removed with Z-effect and secondary varus deformity at 6 months following surgery without any additional surgical intervention.

Femoral head screws were removed in four patients $(2.6 \%)$. They were removed in two patients $(1.3 \%)$ with Z-effect and secondary varus deformity - one patient $(0.6 \%)$ had implant cutout and the other patient $(0.6 \%)$ had reverse Z-effect and secondary varus deformity. Among these four patients, two (1.3\%) underwent partial hip arthroplasty.

A total of seven patients (4.6\%) had thigh pain due to the nail-point effects. Femoral head screws were shortened in one patient $(0.6 \%)$ because they caused trochanteric bursitis due to nail-point effect. The nail was removed in another patient $(0.6 \%)$ because of nail-point-effect-related femoral fractures, and the patient underwent partial hip arthroplasty (Figure 2).

Table 3 Late complications and surgical procedures

\begin{tabular}{ll}
\hline & Cases \\
\hline Late complications & 13 \\
Secondary varus deformity & 4 \\
Neck screw cutout & 3 \\
Z-effect & 2 \\
Reverse Z-effect & 7 \\
Muscle pain (due to nail-point effect) & 4 \\
Fracture of distal locking screw & 3 \\
Nonunion & \\
Surgical procedures & 6 \\
Partial hip arthroplasty & I \\
DCS & 1 \\
Shortening of femoral head screw & 2 \\
Total hip arthroplasty & I \\
Removal of PFN & 3 \\
Removal of femoral head screws &
\end{tabular}

Abbreviations: PFN, proximal femoral nail; DCS, dynamic condylar screw. 
A

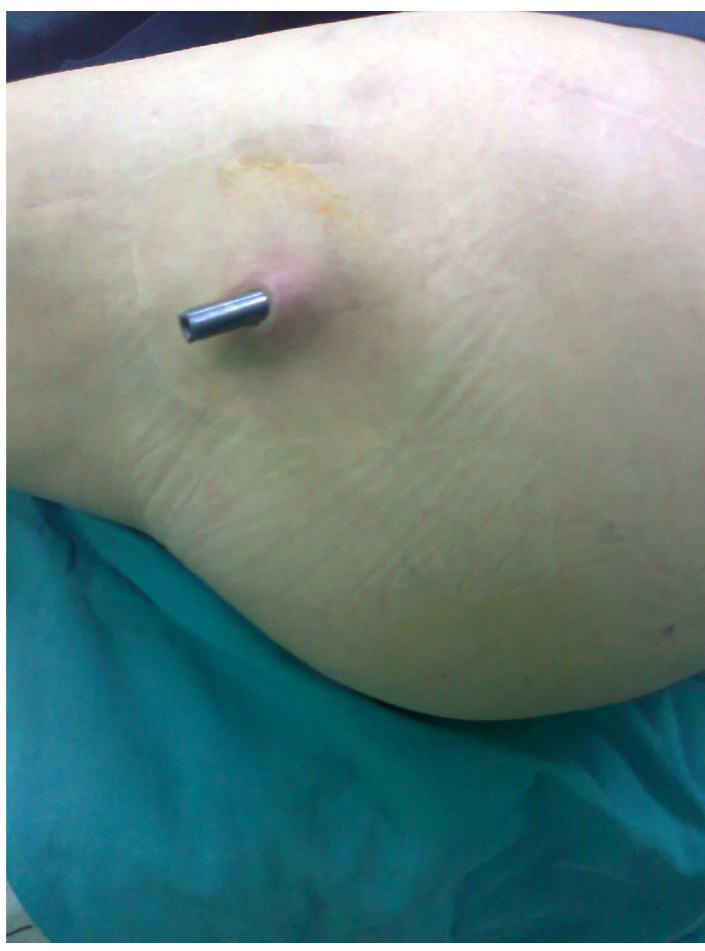

Figure I (A and B) Images of lateral migration of PFN head screws and cutout. Abbreviation: PFN, proximal femoral nail.

The SWS score was not significantly associated with the fracture type, age, sex, and time from fracture to surgery ( $P=0.051, P=0.628, P=0.608$, and $P=0.462$, respectively). A postoperative SWS score of very good correlated with an excellent reduction in the early postoperative stage. We found a significant association between SWS score and reduction quality $\left(\chi^{2}=35.446, P=0.000\right)$.

Furthermore, the patients with mechanical failure had a lower SWS score $\left(\chi^{2}=68.538, P=0.000\right)$. On the basis of radiographic assessment, these patients also were found to have a poor reduction in the early stage $\left(\chi^{2}=39.261, P=0.000\right)$. Mechanical failure was not significantly associated with the fracture type and age ( $P=0.597$ and $P=0.531)$.

In addition, the necessity of a revision procedure was not significantly associated with the fracture type and age ( $P=0.478$ and $P=0.407$, respectively). Early postoperative imaging studies revealed a poor reduction in patients who underwent revision procedures $\left(\chi^{2}=11.823, P=0.003\right)$. Revision procedures were significantly associated with mechanical failure $\left(\chi^{2}=56.699, P=0.000\right)$.

\section{Discussion}

The complication rate of $\mathrm{PFN}$ and the related necessity of a revision procedure varies from $3 \%$ to $28 \%$ in the literature. ${ }^{2,3,7,8,10,11,16-20,23-25}$ Consistent with the published data,

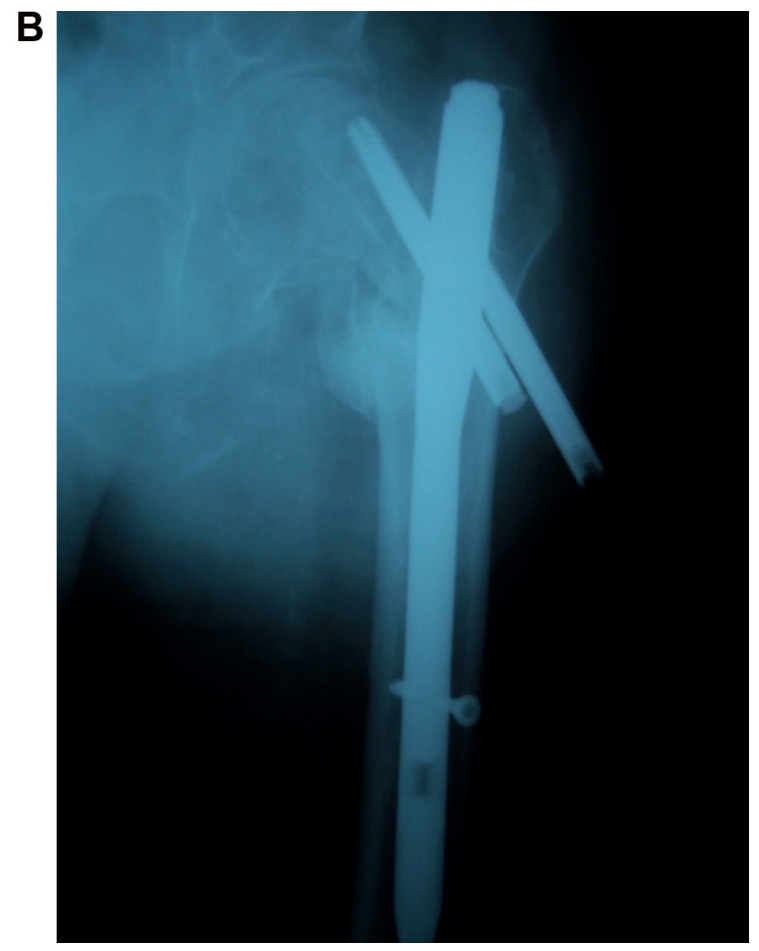

the revision rate related to $\mathrm{PFN}$ osteosynthesis was not high in our study $(9.2 \% ; n=14 / 152)$.

In a series of 191 fractures, Simmermacher et $\mathrm{al}^{20}$ reported an overall technical failure rate of $4.6 \%$. In another study including 178 patients, Appelt et al ${ }^{1}$ reported a complication rate of $15.2 \%(n=27)$. In a case series including 47 peritrochanteric fractures, Fogagnolo et $\mathrm{al}^{2}$ found mechanical failures in $23.4 \%$ patients $(n=11)$. In another case series including 80 patients, Akan et al ${ }^{13}$ observed technical complications in $10 \%$ patients $(n=8)$. In a prospective study including 55 patients treated with PFN, Boldin et $\mathrm{a}^{24}$ reported a complication rate of $21.8 \%$ patients $(n=12)$. Similar to the previous findings, our study showed that the rate of late complications following surgery was $17.7 \%$ (27 patients).

In a study including 295 patients, Domingo et al $^{11}$ reported that ten patients $(3.3 \%)$ who required a revision procedure had AO type 2 and type 3 fractures. Similarly, Simmermacher et $\mathrm{al}^{20}$ concluded that PFN-related complications were mostly associated with AO type 2 fractures. In the present study, among 16 patients with moderate or poor SWS scores, 13 and three had AO type 2 and type 3 fractures, respectively. Of the patients who underwent revision, one patient had type A1 fractures, eight patients had type A2 fractures, and four patients had type A3 fractures. 

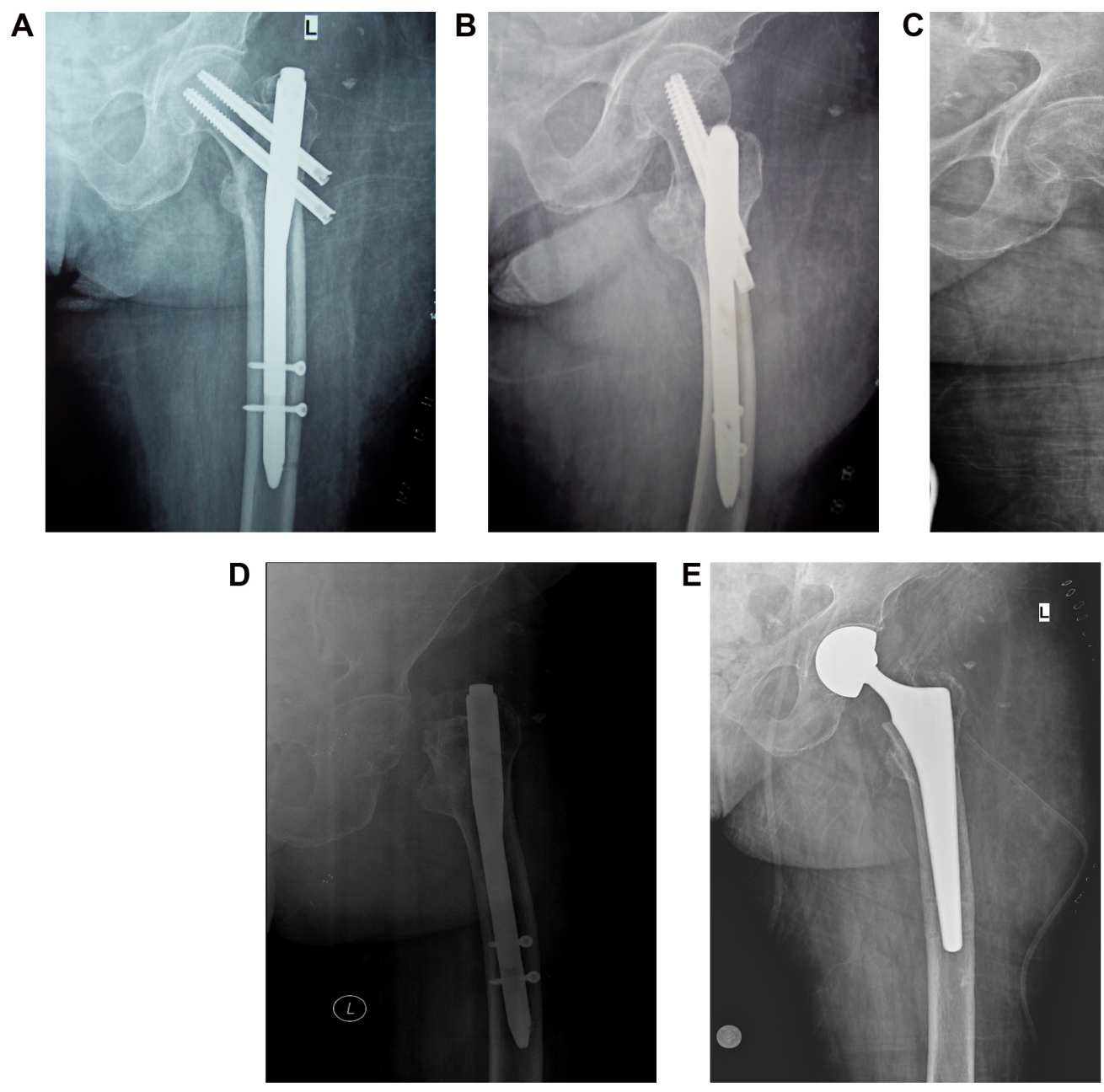

Figure 2 (A-E) Femoral head fracture due to the lateral thigh pain in a patient in whom PFN screws were removed undergoing partial hip arthroplasty. Abbreviation: PFN, proximal femoral nail.

In addition, PFN-related secondary varus deformities may occur in $0.8 \%-8.6 \%$ patients. ${ }^{8,10,11,16,19}$ Consistent with the published literature, our study found PFN-related secondary varus deformities in $8.5 \%$ of the patients (13 patients). According to the $\mathrm{AO}$ classification, among these 13 patients, nine patients had type A2 and four patients had type A3 fractures.

Furthermore, malpositioning of screws or placement of screws with an inappropriate size may lead to cutout from the femoral head. ${ }^{3,10,11,16,17}$ Several studies have reported a cutout rate of $2 \%-8 \%{ }^{3,7,8,11,13-18,24}$ We observed a cut-out complication in four patients $(2.6 \%)$. Two of them underwent partial hip arthroplasty, whereas the remaining two underwent total hip arthroplasty.

The Z-effect phenomenon is a potential complication of double lag screw intramedullary nail designs, ${ }^{25-27}$ and the term was first introduced by Werner-Tutschku et $\mathrm{al}^{26}$ in five $(7.1 \%)$ of 70 patients. The Z-effect and reverse Z-effect phenomena were reported in five patients $(11.1 \%)$ and in one patient $(2.2 \%)$, respectively, in the Tyllianakis et al study ${ }^{8}$ in one patient $(1.2 \%)$ and in three patients $(3.7 \%)$, respectively, in the Akan et al study, ${ }^{13}$ in three patients (5.4\%) and in two patients (3.6\%), respectively, in the Boldin et al study; ${ }^{24}$ and in four patients $(3.3 \%)$ and in one patient $(0.8 \%)$, respectively, in the Papasimos et al study. ${ }^{25}$ Similar to the former studies, we observed Z-effect and reverse Z-effect in three (1.9\%) and two patients $(1.3 \%)$, respectively. One of the patients underwent a partial hip arthroplasty, whereas femoral head screws were removed in three patients. PFN was removed without any additional surgical intervention in another patient.

Calcification of the tip of the greater trochanter is a late radiographic complication with PFN insertion. A total of 13 of 295 patients suffered from this complication in the Domingo et al study, ${ }^{11}$ whereas Herrera et a ${ }^{19}$ reported six patients with calcification of the tip of the greater trochanter. 
In another study, Uzun et $\mathrm{al}^{16}$ found calcification of the tip of the greater trochanter in two patients. Menezes et $\mathrm{al}^{10}$ reported heterotopic ossification in nine out of 129 patients. Unlike these findings, none of the patients showed radiographic evidence of calcification in our study.

In addition, seven patients $(4.6 \%)$ presented with thigh pain due to the nail-point effects. As a late complication, thigh pain was reported to be $2.7 \%$ (eight out of 295) and 3.2\% (four out of 125) by Domingo et $\mathrm{al}^{11}$ and Herrera et al, ${ }^{19}$ respectively.

The use of a double lag screw intramedullary nail design and cortical hypertrophy of the distal locking screw region due to thick distal nails can be associated with thigh pain during the recovery period. ${ }^{11,12,28}$ In the present study, two distal locking screws were used in 140 patients $(92.2 \%)$, whereas a single distal locking screw was used in 12 patients $(7.8 \%)$. The distal locking screw was broken in four patients $(2.6 \%)$.

As a result, PFN is a relatively easy-to-use and effective device in the treatment of unstable trochanteric femoral fractures. , $8,11,12,29$ It enables early postoperative ambulation with a biomechanically stable structure. ${ }^{2,11}$ In addition to using an appropriate implant, adequate reduction quality, proper implant insertion, and the experience of the surgeon play a key role in the successful osteosynthesis for trochanteric fractures. ${ }^{1,8,29-31}$ Windolf et al $^{29}$ reported that the major causes of poor outcomes included poor fracture reduction and the use of an inappropriate screw. Osteosynthesis with PFN is a safe method for simple trochanteric fractures with excellent bone quality; however, PFN may not be the preferred method of fixation for complex fractures in patients with poor bone quality. ${ }^{1}$ In our study, poor reduction was significantly associated with increased mechanical failure and revision rates. However, the fracture type was not significantly associated with mechanical failure.

This study has some limitations. First, there is no control group, including an alternative treatment modality other than PFN. Second, we were unable to investigate the effects of comorbidities such as cognitive status, health status, and activity level, all of which may likely affect the outcomes. The preoperative comorbid factors can have influence on the development of mechanical complications. Third, PFN implants from diverse manufacturers can also have influence on the development of mechanical failure.

In conclusion, the quality of fracture reduction is an important factor that affects the revision rate and SWS score in patients with mechanical complications after PFN was used for trochanteric fractures.

\section{Disclosure}

The authors report no conflicts of interest in this work.

\section{References}

1. Appelt A, Suhm N, Baier M, Meeder PJ. Complications after intramedullary stabilization of proximal femur fractures: a retrospective analysis of 178 patients. Eur J Trauma Emerg Surg. 2007;33(3):262-267.

2. Fogagnolo F, Kfuri M Jr, Paccola CA. Intramedullary fixation of pertrochanteric hip fractures with the short AOASIF proximal femoral nail. Arch Orthop Trauma Surg. 2004;124(1):31-37.

3. Schipper IB, Steyerberg EW, Castelein RM, et al. Treatment of unstable trochanteric fractures. Randomised comparison of the gamma nail and the proximal femoral nail. J Bone Joint Surg Br. 2004;86(1):86-94.

4. Korkmaz MF, Erdem MN, Disli Z, Selcuk EB, Karakaplan M, Gogus A. Outcomes of trochanteric femoral fractures treated with proximal femoral nail: an analysis of 100 consecutive cases. Clin Interv Aging. 2014; 3(9):569-574.

5. White BL, Fisher WD, Laurin CA. Rate of mortality for elderly patients after fracture of the hip in the1980's. J Bone Joint Surg Am. 1987; 69(9):1335-1340.

6. Zuckerman JD, Skovron ML, Koval KJ, Aharonoff G, Frankel VH. Postoperative complications and mortality associated with operative delay in older patients who have a fracture of the hip. $J$ Bone Joint Surg Am. 1995;77(10):1551-1556.

7. Banan H, Al-Sabti A, Jimulia T, Hart AJ. The treatment of unstable, extracapsular hip fractures with the AO/ASIF proximal femoral nail (PFN) - our first 60 cases. Injury. 2002;33(5):401-405.

8. Tyllianakis M, Panagopoulos A, Papadopoulos A, Papasimos S, Mousafiris K. Treatment of extracapsular hip fractures with the proximal femoral nail (PFN): long term results in 45 patients. Acta Orthop Belg. 2004;70(5):444-454.

9. Müller ME, Nazarian S, Koch P, Schatzker J. The Comprehensive Classification of Fractures of Long Bones. Berlin, Germany: SpringerVerlag; 1990.

10. Menezes DF, Gamulin A, Noesberger B. Is the proximal femoral nail a suitable implant for treatment of all trochanteric fractures? Clin Orthop Relat Res. 2005;439:221-227.

11. Domingo LJ, Cecilia D, Herrera A, Resines C. Trochanteric fractures treated with a proximal femoral nail. Int Orthop. 2001;25(5): 298-301.

12. Ozkan K, Unay K, Demircay C, Cakir M, Eceviz E. Distal unlocked proximal femoral intramedullary nailing for intertrochanteric femur fractures. Int Orthop. 2009;33(5):1397-1400.

13. Akan K, Cift H, Ozkan K, Eceviz E, Tasyikan L, Eren A. Effect of osteoporosis on clinical outcomes in intertrochanteric hip fractures treated with a proximal femoral nail. J Int Med Res. 2011;39(3): 857-865.

14. Ma KL, Wang X, Luan FJ, et al. Proximal femoral nails antirotation, Gamma nails, and dynamic hip screws for fixation of intertrochanteric fractures of femur: a meta-analysis. Orthop Traumatol Surg Res. 2014; 100(8):859-866.

15. Shen L, Zhang Y, Shen Y, Cui Z. Antirotation proximal femoral nail versus dynamic hip screw for intertrochanteric fractures: a meta-analysis of randomized controlled studies. Orthop Traumatol Surg Res. 2013; 99(4):377-383.

16. Uzun M, Ertürer E, Oztürk I, Akman S, Seçkin F, Ozçelik IB. Longterm radiographic complications following treatment of unstable intertrochanteric femoral fractures with the proximal femoral nail and effects on functional results. Acta Orthop Traumatol Turc. 2009;43(6):457-463.

17. Erturer RE, Sönmez MM, Sari S, Seckin MF, Kara A, Ozturk I. Intramedullary osteosynthesis of instable intertrochanteric femur fractures with Profin ${ }^{\circledR}$ nail in elderly patients. Acta Orthop Traumatol Turc. 2012; 46(2):107-112. 
18. Saudan M, Lübbeke A, Sadowski C, Riand N, Stern R, Hoffmeyer P. Pertrochanteric fractures: is there an advantage to an intramedullary nail? A randomized, prospective study of patients comparing the dynamic hip screw and proximal femoral nail. J Orthop Trauma. 2002; 16(6):386-393.

19. Herrera A, Domingo LJ, Calvo A, Martínez A, Cuenca J. A comparative study of trochanteric fractures treated with the Gamma nail or the proximal femoral nail. Int Orthop. 2002;26(6):365-369.

20. Simmermacher RK, Bosch AM, Van der Werken C. The AO/ASIFproximal femoral nail (PFN): a new device for the treatment of unstable proximal femoral fractures. Injury. 1999;30(5):327-332.

21. Baumgaertner MR, Curtin SL, Lindskog DM. Intramedullary versus extramedullary fixation for the treatment of intertrochanteric hip fractures. Clin Orthop Relat Res. 1998;348:87-94.

22. Salvati EA, Wilson PD. Long term results of femoral-head replacement. J Bone Joint Surg. 1973;55(3):516-524.

23. Al-yassari G, Langstaff RJ, Jones JW, Al-Lami M. The AO/ASIF proximal femoral nail (PFN) for the treatment of unstable trochanteric femoral fracture. Injury. 2002;33(5):395-399.

24. Boldin C, Seibert FJ, Fankhauser F, Peicha G, Grechenig W, Szyszkowitz R. The proximal femoral nail (PFN)-a minimal invasive treatment of unstable proximal femoral fractures: a prospective study of 55 patients with a follow-up of 15 months. Acta Orthop Scand. 2003; 74(1):53-58.
25. Papasimos S, Koutsojannis CM, Panagopoulos A, Megas P, Lambiris E A randomised comparison of AMBI, TGN and PFN for treatment of unstable trochanteric fractures. Arch Orthop Trauma Surg. 2005; 125(7):462-468

26. Werner-Tutschku W, Lajtai G, Schmiedhuber G, Lang T, Pirkl C, Orthner E. Intra- and perioperative complications in the stabilization of per- and subtrochanteric femoral fractures by means of PFN. Unfallchirurg. 2002;105(10):881-885.

27. Strauss EJ, Kummer FJ, Koval KJ, Egol KA. The "Z-effect" phenomenon defined: a laboratory study. J Orthop Res. 2007;25(12):1568-1573.

28. Hardy DC, Descamps PY, Krallis P, et al. Use of an intramedullary hip-screw compared with a compression hip-screw with a plate for intertrochanteric femoral fractures. A prospective, randomized study of one hundred patients. J Bone Joint Surg Am. 1998;80(5):618-630.

29. Windolf J, Hollander DA, Hakimi M, Linhart W. Pitfalls and complications in the use of the proximal femoral nail. Langenbecks Arch Surg. 2005;390(1):59-65.

30. Baumgaertner MR, Curtin SL, Lindskog DM, Keggi JM. The value of the tip-apex distance in predicting failure of peritrochanteric fractures of the hip. J Bone Joint Surg Am. 1995;77(7):1058-1064.

31. Biber R, Grüninger S, Singler K, Sieber CC, Bail HJ. Is proximal femoral nailing a good procedure for teaching in orthogeriatrics? Arch Orthop Trauma Surg. 2012;132(7):997-1002.
Clinical Interventions in Aging

\section{Publish your work in this journal}

Clinical Interventions in Aging is an international, peer-reviewed journal focusing on evidence-based reports on the value or lack thereof of treatments intended to prevent or delay the onset of maladaptive correlates of aging in human beings. This journal is indexed on PubMed Central, MedLine,

\section{Dovepress}

CAS, Scopus and the Elsevier Bibliographic databases. The manuscript management system is completely online and includes a very quick and fair peer-review system, which is all easy to use. Visit http://www.dovepress. com/testimonials.php to read real quotes from published authors. 